\title{
Isotope Fractionation Pinpoints Membrane Permeability as a Barrier to Atrazine Biodegradation in Gram-negative Polaromonas sp. Nea-C
}

\author{
Benno N. Ehrl, ${ }^{\dagger}$ Mehdi Gharasoo, $^{\dagger}$ and Martin Elsner ${ }^{*}, \dagger, \ddagger$ (이 \\ ${ }^{\dagger}$ Institute of Groundwater Ecology, Helmholtz Zentrum München, Ingolstädter Landstrasse 1, 85764 Neuherberg, Germany \\ ${ }^{\ddagger}$ Chair of Analytical Chemistry and Water Chemistry, Technical University of Munich, Marchioninistrasse 17, 81377 Munich, \\ Germany
}

\section{Supporting Information}

ABSTRACT: Biodegradation of persistent pesticides like atrazine often stalls at low concentrations in the environment. While mass transfer does not limit atrazine degradation by the Gram-positive Arthrobacter aurescens $\mathrm{TC} 1$ at high concentrations $(>1 \mathrm{mg} / \mathrm{L})$, evidence of bioavailability limitations is emerging at trace concentrations $(<0.1 \mathrm{mg} / \mathrm{L})$. To assess the bioavailability constraints on biodegradation, the roles of cell wall physiology and transporters remain imperfectly understood. Here, compound-specific isotope analysis (CSIA) demonstrates that cell wall physiology (i.e., the difference between Gram-negative and Gram-positive bacteria) imposes mass transfer limitations in atrazine biodegradation even at high concentrations. Atrazine biodegradation by Gram-negative

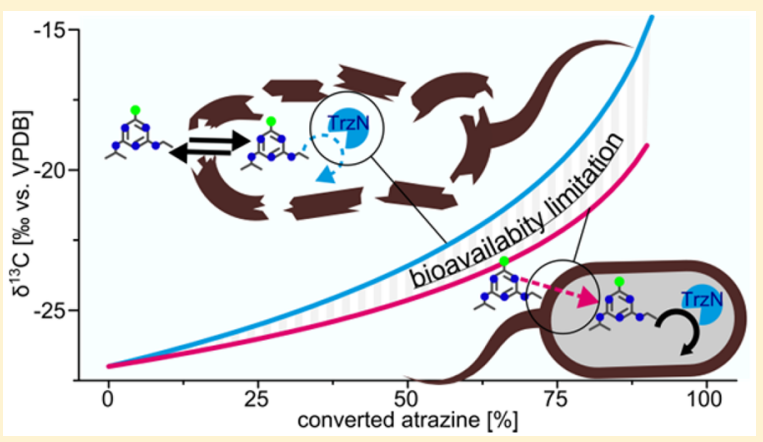
Polaromonas $s p$. Nea-C caused significantly less isotope fractionation $(\varepsilon(\mathrm{C})=-3.5 \%$ ) than expected for hydrolysis by the enzyme $\operatorname{TrzN}(\varepsilon(\mathrm{C})=-5.0 \%$ ) and observed in Gram-positive Arthrobacter aurescens TC1 $(\varepsilon(\mathrm{C})=-5.4 \%$ ). Isotope fractionation was recovered in cell-free extracts $(\varepsilon(C)=-5.3 \%$ ) where no cell envelope restricted pollutant uptake. When active transport was inhibited with cyanide, atrazine degradation rates remained constant demonstrating that atrazine mass transfer across the cell envelope does not depend on active transport but is a consequence of passive cell wall permeation. Taken together, our results identify the cell envelope of the Gram-negative bacterium Polaromonas sp. Nea-C as a relevant barrier for atrazine biodegradation.

\section{INTRODUCTION}

Groundwater contamination by micropollutants is a prominent challenge of our time. Since ground and surface waters represent an important drinking water resource, the presence of micropollutants is of concern not only for ecosystems but also for human health. ${ }^{1}$ Because of their ubiquitous release and their low concentrations, however, evaluating the fate of micropollutants in the environment is complex. Pharmaceuticals are discharged into the environment with wastewater treatment effluents, ${ }^{2-4}$ and pesticides used in agriculture even directly leach into groundwater on a large scale. ${ }^{5,6} \mathrm{EU}$ regulations on drinking water quality set a maximum concentration of $0.1 \mu \mathrm{g} / \mathrm{L}$ for pesticides and their degradation products (European Union Drinking Water Directive, 98/83/ EC). How difficult it is, however, to relate successful biodegradation in the lab to the fate of pesticides in the environment, is illustrated by the herbicide atrazine: even though it was banned in the EU as long ago as 2003, atrazine and its metabolites are still the groundwater contaminants most frequently detected above this threshold concentration. ${ }^{7}$ The underlying bottlenecks of biodegradation at trace concentrations which cause this persistence have eluded researchers for years. Even though atrazine is initially adsorbed and retained to some extent on soil and sediments, ${ }^{8}$ the pesticide becomes available at low concentrations $(\mu \mathrm{g} / \mathrm{L})$ for atrazine degrading bacteria. ${ }^{9,10}$ For such a situation, competing models claim that it is either mass transfer (uptake into microbial cells) which puts a limit to otherwise rapid enzymatic transformation ${ }^{11,12}$ or physiological limitations (enzyme activity, downregulation) that prevail. ${ }^{13}$ Compound-specific isotope analysis (CSIA) provides a way to directly visualize the rate-determining step of pollutant biodegradation: ${ }^{14}$ Chemical bond breakage during pollutant degradation is slower when the bond contains a heavy isotope since the respective activation energy is higher. Therefore, the remaining pollutant molecules contain on average increasingly more heavy isotopes as an enzymatic reaction proceeds. ${ }^{15}$ This trend can be described by relating the change in isotope ratios $\left(R_{t} / R_{\mathrm{o}}\right)$ to the fraction of the remaining pollutant $f$ according to the Rayleigh eq $1^{16,17}$

$$
\ln \left(\frac{R_{t}}{R_{0}}\right)=\varepsilon \times \ln (f)
$$

Received: December 22, 2017

Revised: March 1, 2018

Accepted: March 2, 2018

Published: March 2, 2018 
where the enrichment factor $\varepsilon$ reflects the incremental isotope fractionation during transformation. This isotope effect, however, can only be observed if substrate molecules experiencing the isotopic discrimination during the enzymatic reaction in the cytosol diffuse back out into the bulk solution, where the isotope ratio is assessed. Thus, any partially ratedetermining step preceding the irreversible enzymatic turnover (e.g., mass transfer) will lead to a reduced exchange of "enriched" substrate molecules to the outside of the cell. As a consequence, the observable isotope enrichment factor $\varepsilon$ will be smaller, since the reduced exchange masks the isotope fractionation of the enzymatic reaction. ${ }^{18,19}$ Masked isotope fractionation due to mass transfer limitations is well understood from photosynthesis, ${ }^{20,21}$ sulfate reduction, ${ }^{22-24}$ or nitrate reduction. $^{25,26}$ The same effect has previously been demonstrated for organic pollutants taken up by active transport ${ }^{27}$ and for nonpolar chlorinated ethenes. ${ }^{19,28}$ A conceptual framework has been brought forward by Thullner et al. to mathematically predict the effect for passive permeation of organic pollutants through a biological double membrane. ${ }^{29,30}$ Based on these studies, we recently discovered that cell wall permeation was not relevant for atrazine biodegradation by Arthrobacter aurescens TC1 at high concentrations but became suddenly rate-limiting at low concentrations (low microgram per liter range). ${ }^{31}$ This finding is challenged by earlier observations by Meyer et al. that even at high concentrations, isotope fractionation in atrazine degradation varied significantly between bacterial strains catalyzing the same reaction. ${ }^{32}$ Usually, the isotope fractionation factor is assumed to be characteristic for a specific transformation pathway if the underlying enzyme reaction is identical. ${ }^{33-35}$ A compelling clue to explain the results of Meyer et al., is, therefore, the fact that differences exist between Gram-negative and Gram-positive bacterial strains. The additional outer membrane in Gramnegative strains possibly constitutes an additional barrier for mass transfer which can mask the enzymatic isotope fractionation. Indeed, Renpenning et al. observed that carbon isotope fractionation during chlorinated ethene degradation differed for Gram-positive and Gram-negative bacteria and depended on the integrity of the cell envelope. ${ }^{28}$ In the case of Meyer et al., however, this proposed causal relationship could not be uniquely pinpointed because different enzymes of the same family (AtzA vs TrzN) were involved. Consequently, it could not be excluded that the observed variability may, alternatively, be attributable to subtle variations in transition state structures.

We, therefore, systematically addressed the question in our study by exploiting the opportunity that the Gram-negative bacterium, Polaromonas sp. Nea-C, harbors the same set of intracellular atrazine degrading enzymes ${ }^{36}$ as the Gram-positive A. aurescens TC1 (TrzN, AtzB, AtzC). ${ }^{32,37}$ Atrazine hydrolysis by $\operatorname{TrzN}\left(\mathrm{K}_{\mathrm{M}}=19 \mu \mathrm{M}, k_{\text {cat }}=5.5 \mathrm{~s}^{-1}\right)$ proceeds via initial protonation of the ring nitrogen and subsequent hydrolysis of the $\mathrm{C}-\mathrm{Cl}$ bond. ${ }^{36,38}$ Further, enrichment factors of the degradation reaction in whole cells are similar to those of the degradation with purified TrzN without cell envelope meaning that atrazine degradation by whole cells of Gram-positive $A$. aurescens TC1 is not mass transfer-limited. ${ }^{38}$ We compared the isotope fractionation during atrazine degradation with intact cells of Gram-negative Polaromonas sp. Nea-C-a scenario in which mass transfer across the cell envelope can matterrelative to degradation with Gram-positive A. aurescens TC1, cell-free extracts of Gram-negative Polaromonas sp. Nea-C, or purified TrzN enzyme: ${ }^{38}$ three scenarios in which mass transfer is absent. Furthermore, we addressed the possibility of active transport to clarify whether passive membrane permeation of atrazine is sufficient to provide enough influx for those bacteria to sustain growth. To this end, we investigated whether atrazine degradation rates of Polaromonas sp. Nea-C and A. aurescens TC1 were affected when active transport was inhibited by the respiratory chain inhibitor potassium cyanide $(\mathrm{KCN})$.

\section{EXPERIMENTAL SECTION}

Chemicals. A list of chemicals used can be found in the Supporting Information.

Cultivation of Bacteria. Polaromonas sp. Nea-C was kindly provided by Fabrice Martin-Laurent (Microbiologie du Sol et de l'Environnement, INRA, France), and Arthrobacter aurescens TC1 was kindly provided by Larry Wackett (The BioTechnology Institute, University of Minnesota, USA). All strains were grown in liquid mineral salt medium (MSM) containing a nitrogen source (for composition see the Supporting Information). Excess atrazine above the solubility limit was added in solid form to a concentration of $500 \mathrm{mg} / \mathrm{L}$ to provide enough nutrient for high cell densities. Cultures were incubated at room temperature $\left(25{ }^{\circ} \mathrm{C}\right)$.

Atrazine Degradation with Whole Cells of Polaromonas sp. Nea-C for Isotope Analysis. Growth of a freshly inoculated culture $(500 \mathrm{~mL})$ of Polaromonas $s p$. Nea-C was followed by monitoring the optical density $\left(\mathrm{OD}_{600}\right)$. During exponential phase $\left(\mathrm{OD}_{600}=0.05\right)$ cells were pelleted by centrifugation (Heraeus Megafuge 40R, Thermo Scientific, TX-1000 rotor, $3700 \mathrm{~g}, 30 \mathrm{~min}, 4^{\circ} \mathrm{C}$ ) and washed twice in $50 \mathrm{~mL}$ MSM to remove the remaining atrazine. After those washing steps, the cell pellet was resuspended in $500 \mathrm{~mL}$ of fresh MSM containing $30 \mathrm{mg} / \mathrm{L}$ atrazine. The atrazine concentration was close to the solubility limit of $33 \mathrm{mg} / \mathrm{L}$ (see media preparation in the SI) to maximize the amount of substance per volume and, hence, to minimize the necessary sample volume for reliable isotope analysis (see below). ${ }^{39}$ The degradation experiment lasted approximately $24 \mathrm{~h}$ and the atrazine concentration was monitored by HPLC-UV (see below). For each of the three biological replicates, 5 samples for isotope analysis were taken $(20 \mathrm{~mL}$ in the beginning and 50, 70, 150, $200 \mathrm{~mL}$ at approximately $50 \%, 75 \%, 85 \%$, and $95 \%$ atrazine consumption respectively). The degradation reaction was stopped by sterile filtration with a regenerated cellulose membrane filter (pore size $0.2 \mu \mathrm{m}$, diameter $47 \mathrm{~mm}$; GE Healthcare ltd., UK). The biomass and the filter volume were not extracted, as their volume $(<0.5 \mathrm{~mL})$ is negligible compared to the filtrate $(>20$ $\mathrm{mL})$. The filtrate was extracted three times with $10 \%(\mathrm{v} / \mathrm{v})$ dichloromethane. The combined dichloromethane extracts were evaporated under an air stream and the samples were reconstituted in $100 \mu \mathrm{L}$ ethyl acetate for GC-IRMS measurements (see below).

Preparation of Cell-Free Extracts of Polaromonas sp. NeaC. Polaromonas $s p$. Nea-C cells were grown and harvested as described above. The cell pellet was resuspended in $5 \mathrm{~mL}$ of fresh MSM and put on ice. Cell membranes were disrupted in two passages by a French pressure cell (American Instrument Company, USA, 3/8 in. piston diameter, 20000 psi). Remaining whole cells and cell fragments were removed by sterile filtration with a regenerated cellulose membrane filter (pore size $0.2 \mu \mathrm{m}$, diameter $47 \mathrm{~mm}$; GE Healthcare ltd., UK), and the extract was stored on ice for a short time for the degradation experiment. 
Table 1. Overview of Isotope Fractionation during Atrazine Degradation via Acidic Hydrolysis in Different Experimental Setups $^{a}$

\begin{tabular}{|c|c|c|c|c|c|c|c|}
\hline experimental system & enzyme & Gram stain & $\varepsilon(\mathrm{C})(\% \circ)$ & $\varepsilon(\mathrm{N})(\% o)$ & $\lambda \approx \varepsilon(\mathrm{N}) / \varepsilon(\mathrm{C})$ & concentration $(\mathrm{mg} / \mathrm{L})$ & ref \\
\hline whole cells Polaromonas sp. Nea-C & TrzN & negative & $-3.5 \pm 0.1$ & $1.9 \pm 0.1$ & $-0.55 \pm 0.04$ & $30-1.4$ & this study \\
\hline cell-free extract Polaromonas sp. Nea-C & TrzN & negative & $-5.3 \pm 0.7$ & $3.2 \pm 0.5$ & $-0.60 \pm 0.14$ & $30-2.8$ & this study \\
\hline whole cells $A$. aurescens $\mathrm{TC} 1$ & TrzN & positive & $-5.4 \pm 0.6$ & $3.3 \pm 0.4$ & $-0.61 \pm 0.02$ & $18-1.3$ & 32 \\
\hline purified $A$. aurescens TC1 TrzN & TrzN & positive & $-5.0 \pm 0.2$ & $2.5 \pm 0.1$ & $-0.54 \pm 0.02$ & $24-3$ & 38 \\
\hline Chelatobacter heintzii & AtzA & negative & $-3.7 \pm 0.2$ & $2.3 \pm 0.4$ & $-0.65 \pm 0.08$ & $15-1.8$ & 32 \\
\hline abiotic pH $360^{\circ} \mathrm{C}$ & & & $-4.8 \pm 0.4$ & $2.5 \pm 0.2$ & $-0.52 \pm 0.04$ & $24-3$ & 32 \\
\hline
\end{tabular}

${ }^{a}$ Uncertainties represent $95 \%$ confidence intervals.

Atrazine Degradation with Cell-Free Extracts of Polaromonas sp. Nea-C for Isotope Analysis. The $5 \mathrm{~mL}$ concentrated cell-free extract was diluted in $250 \mathrm{~mL}$ of fresh MSM containing $30 \mathrm{mg} / \mathrm{L}$ atrazine. The atrazine concentration over time was monitored by HPLC-UV (see below) by taking samples for $4 \mathrm{~h}$. For each of the three biological replicates, 5 samples for isotope analysis were taken $(10 \mathrm{~mL}$ in the beginning and $15,35,60,120 \mathrm{~mL}$ at approximately $60 \%, 80 \%$, $90 \%$, and $95 \%$ atrazine consumption, respectively), and the degradation reaction was stopped by extracting atrazine three times with $10 \%(\mathrm{v} / \mathrm{v})$ dichloromethane. The extracts were concentrated for GC-IRMS as described above.

Atrazine Degradation Rates with and without Respiratory Chain Inhibitor KCN. Growth of freshly inoculated cultures (50 $\mathrm{mL}$ ) of both Polaromonas sp. Nea-C and A. aurescens TC1 was followed by $\mathrm{OD}_{600}$, and cell numbers per milliliter were estimated for both strains with $8 \times 10^{8}$ cells $/\left(\mathrm{mL} \mathrm{OD}_{600}\right)$. The cells were harvested as described above and the cell pellet was resuspended in $50 \mathrm{~mL}$ of fresh MSM. For both species, each of the three biological replicates was split in $2 \times 25 \mathrm{~mL}$ cell suspensions to get the same biomass for the inhibited and the noninhibited degradation experiment. To inhibit the respiratory chain, $0.25 \mathrm{mM} \mathrm{KCN}$ was added to one cell suspension. Afterward, atrazine was added to both cell suspensions at a concentration of $3 \mathrm{mg} / \mathrm{L}$. A small initial atrazine concentration was chosen to ensure short degradation times to rule out growth of the noninhibited cells during the experiment. The atrazine concentration over time was monitored by HPLC-UV for $4 \mathrm{~h}$ (see below). Because Polaromonas sp. Nea-C and $A$. aurescens $\mathrm{TC} 1$ might have different $\mathrm{TrzN}$ abundances, we only compared each strain with and without inhibition and not the degradation kinetics of Polaromonas sp. Nea-C versus $A$. aurescens $\mathrm{TC} 1$.

Determination of the Atrazine Concentration by HPLCUV. Atrazine concentrations were measured using a Prominence HPLC system (Shimadzu Corp., Japan) together with a $100 \mathrm{~mm} \times 4.6 \mathrm{~mm}$ Kinetex $5 \mu$ Biphenyl $100 \AA$ column equipped with a SecurityGuard ULTRA Biphenyl cartridge (both Phenomenex Inc., USA). The injected sample volume was $10 \mu \mathrm{L}$. Peak separation was achieved by $1 \mathrm{~mL} / \mathrm{min}$ isocratic flow of a mixture of $51 \% 5 \mathrm{mM} \mathrm{KH_{2 }} \mathrm{PO}_{4}$ buffer at $\mathrm{pH} 7$ and $49 \%$ methanol, respectively, for $9 \mathrm{~min}$. The compounds were detected by UV absorbance at $222 \mathrm{~nm}$ and the peaks were quantified using LabSolutions V 5.71 SP2 (Shimadzu Corp., Japan). External calibration was conducted with atrazine dissolved in $25 \%$ methanol and $75 \%$ water in the following concentrations: $0.5,4,12,35 \mu \mathrm{g} / \mathrm{L}$

Carbon and Nitrogen Isotope Measurements with GC-IRMS. The method was adapted from the work of Reinnicke et al. ${ }^{39}$ The GC-IRMS system consisted of a TRACE GC Ultra gas chromatograph (GC; Thermo Fisher
Scientific, Milan, Italy) linked to a Finnigan MAT 253 isotope ratio mass spectrometer (IRMS) (Thermo Fisher Scientific, Germany) by a Finnigan GC Combustion III Interface (Thermo Fisher Scientific, Germany). Helium (grade 5.0) was used as carrier gas and the split injector was kept at $250{ }^{\circ} \mathrm{C}$ with a 1:10 split at a flow rate of $1.4 \mathrm{~mL} / \mathrm{min}$. The samples were injected using a GC Pal autosampler (CTC, Switzerland) onto a $60-\mathrm{m} \mathrm{DB}-5(30 \mathrm{~m} \times 0.25 \mathrm{~mm} ; 1 \mu \mathrm{m}$ film; Restek $\mathrm{GmbH}$, Germany) analytical column. Isotope values were determined as $\delta^{13} \mathrm{C}$ and $\delta^{15} \mathrm{~N}$ values in per mill relative to Vienna PeeDee Belemnite (VPDB) ${ }^{40}$ and Air- $\mathrm{N}_{2} \cdot{ }^{41}$ The $\delta^{13} \mathrm{C}$ and $\delta^{15} \mathrm{~N}$ values were assessed in relation to a monitoring gas $\left(\mathrm{CO}_{2}\right.$ and $\mathrm{N}_{2}$, respectively) which was measured alongside each run at the beginning and the end. Calibration of monitoring gases was performed in a Finnigan MAT Delta $S$ isotope ratio mass spectrometer with dual inlet system (Thermo Fisher Scientific, Germany). The gases were measured against VPDB and air, respectively, by use of international reference materials: the $\mathrm{CO}_{2}$ gases RM 8562, RM 8563, and RM 8564 for $\mathrm{CO}_{2}$ and $\operatorname{NSVEC~}\left(\mathrm{N}_{2}\right.$ gas $)$ for $\mathrm{N}_{2}$. Reference standards were provided by the IAEA. The GC oven started at $65^{\circ} \mathrm{C}$ (hold $3 \mathrm{~min}$ ) and was ramped at $25{ }^{\circ} \mathrm{C} / \mathrm{min}$ to $190{ }^{\circ} \mathrm{C}$ This was followed by a temperature ramp of $15{ }^{\circ} \mathrm{C} / \mathrm{min}$ to $270{ }^{\circ} \mathrm{C}$ which was kept for $20 \mathrm{~min}$.

Modeling of the Isotope Fractionation during the Degradation. In the absence of the cell envelope, the bioavailable concentration close to the enzyme is equal to the bulk concentration in solution. Therefore, the biodegradation of both substrate fractions (molecules containing ${ }^{12} \mathrm{C}$ and ${ }^{13} \mathrm{C}$, short ${ }^{12} \mathrm{~S}$ and ${ }^{13} \mathrm{~S}$ ) follows Michaelis-Menten kinetics ${ }^{42}$ and is described by the set of eqs 2 and $3:^{16}$

$$
\begin{aligned}
& \frac{\mathrm{d}\left[{ }^{12} \mathrm{~S}\right]}{\mathrm{d} t}=-\frac{q_{\max }\left[{ }^{12} \mathrm{~S}\right]}{\left[{ }^{12} \mathrm{~S}\right]+\left[{ }^{13} \mathrm{~S}\right]+K_{\mathrm{M}}} \\
& \frac{\mathrm{d}\left[{ }^{13} \mathrm{~S}\right]}{\mathrm{d} t}=-\frac{\alpha q_{\max }\left[{ }^{13} \mathrm{~S}\right]}{\left[{ }^{12} \mathrm{~S}\right]+\left[{ }^{13} \mathrm{~S}\right]+K_{\mathrm{M}}}
\end{aligned}
$$

where $\alpha$ is the fractionation factor with $\varepsilon=\alpha-1, q_{\max }$ is the maximum degradation rate, and $K_{\mathrm{M}}$ is the half saturation constant of the Michaelis-Menten kinetics. In the presence of mass transfer limitations across the cell envelope it is necessary to distinguish between substrate concentrations outside the cell, $S$, and substrate concentrations inside the cell, $S($ bio), where the exchange rate between these two phases is determined by the mass-transfer coefficient $k_{\mathrm{tr}}{ }^{43,44}$ Including the mass transfer limiting term in eqs 2 and 3 gives eqs 4 and 5 and analogous equations for the heavy fraction, where the last term in eq 5 is multiplied by the fractionation factor $\alpha:^{26}$ 


$$
\begin{aligned}
& \frac{\mathrm{d}\left[{ }^{12} \mathrm{~S}\right]}{\mathrm{d} t}=-k_{\mathrm{tr}}\left(\left[{ }^{12} \mathrm{~S}\right]-\left[{ }^{12} \mathrm{~S}(\text { bio })\right]\right) \\
& \frac{\mathrm{d}\left[{ }^{12} \mathrm{~S}(\text { bio })\right]}{\mathrm{d} t}=+k_{\mathrm{tr}}\left(\left[{ }^{12} \mathrm{~S}\right]-\left[{ }^{12} \mathrm{~S}(\text { bio })\right]\right) \\
&-\frac{q_{\max }\left[{ }^{12} \mathrm{~S}\right]}{\left[{ }^{12} \mathrm{~S}(\text { bio })\right]+\left[{ }^{13} \mathrm{~S}(\text { bio })\right]+K_{\mathrm{M}}}
\end{aligned}
$$

These equations were solved and fitted to the experimental results to obtain the unknown parameters $k_{\text {tr }}$ and the maximum degradation rate $q_{\max }$ using a modified version of ReKinSim. ${ }^{45}$ The enzymatic fractionation factor $\alpha=\varepsilon+1$ was determined by the fit of the Rayleigh eq (eq 1, Table 1) and the value for $K_{\mathrm{M}}=$ $19 \mu \mathrm{mol} / \mathrm{L}$ was taken from the literature. ${ }^{36}$ Equation 6 calculates an estimate of the atrazine diffusion coefficient in lipids, $D_{\text {lip }}$

$$
D_{\text {lip }}=\frac{k_{\text {tr }} \delta V}{A K_{\text {lipw }}}
$$

where $\delta=10 \mathrm{~nm}$ is the thickness of two lipid double membranes ( $5 \mathrm{~nm}$ each) to mimic the Gram-negative cell wall, and $V=0.5 \mathrm{~L}$ is the volume of the cell suspension. $A$ is the bacterial total surface area calculated from an estimate of $4 \times$ $10^{7}$ cells $/ \mathrm{mL}$ (derived from the $\mathrm{OD}_{600}=0.05$ with $8 \times 10^{8}$ cells $\left./\left(\mathrm{mL} \mathrm{OD}_{600}\right)\right)$ and an average bacterial surface of $4 \mu \mathrm{m}^{3}$. $K_{\text {lipw }}=741$ is the lipid-water distribution coefficient of atrazine. $^{46}$

\section{RESULTS AND DISCUSSION}

Atrazine Degradation with Gram-negative Polaromonas sp. Nea-C Induced Smaller Isotope Fractionation than Observed with TrzN. Resting cells of Gramnegative Polaromonas sp. Nea-C with a $\mathrm{OD}_{600}=0.05$ degraded $30 \mathrm{mg} / \mathrm{L}$ atrazine within $24 \mathrm{~h}$ (see SI Figure S1). TrzNcatalyzed atrazine hydrolysis to hydroxyatrazine led to considerable isotope fractionation both for carbon (enrichment of ${ }^{13} \mathrm{C}$ relative to ${ }^{12} \mathrm{C}$ corresponding to a normal isotope effect) and for nitrogen (depletion of ${ }^{15} \mathrm{~N}$ relative to ${ }^{14} \mathrm{~N}$ representing an inverse isotope effect) (Figure 1). This inverse nitrogen isotope effect is characteristic of proton-assisted hydrolysis in the transition state of $\mathrm{TrzN}^{38}$ The enrichment factors for carbon $\varepsilon(\mathrm{C})=-3.5 \% \circ \pm 0.1 \% \circ$ and nitrogen $\varepsilon(\mathrm{N})=1.9 \% 0 \pm$ $0.1 \%$ ( $\pm 95 \%$ confidence intervals $)$ were determined by the Rayleigh equation, as shown in Figure 2A, B. These enrichment factors are significantly smaller than those described for atrazine hydrolysis catalyzed by $\operatorname{TrzN}$, i.e. those obtained during biodegradation with Gram-positive A. aurescens $\mathrm{TCl}^{32}$ (Figure $2 \mathrm{~A}, \mathrm{~B})$. We screened for genes analogous to the $\operatorname{tr} \mathrm{N}$ gene sequence from $A$. aurescens $T C 1^{47}$ in the NCBI database by Blast search ${ }^{48}$ and found more than 20 sequences coding for TrzN with more than $99 \%$ similarity (SI Table S1). Also the isotope fractionation of the abiotic model reaction-acidcatalyzed hydrolysis in water-is stronger than observed in our experiment with Polaromonas $s p$. Nea-C. ${ }^{32}$ Taken together, this evidence is consistent with the hypothesis that a different ratedetermining step-mass transfer across the cell envelopepartially masked the isotope fractionation of the enzyme in Polaromonas sp. Nea-C. Remarkably, the enrichment factors for the Gram-negative Chelatobacter heintzii $(\varepsilon(\mathrm{C})=-3.7 \pm 0.2$ $\% o$ and $\varepsilon(\mathrm{N})=2.3 \pm 0.4 \%$ ) are statistically indistinguishable from Polaromonas sp. Nea-C. Both are Gram-negative bacteria
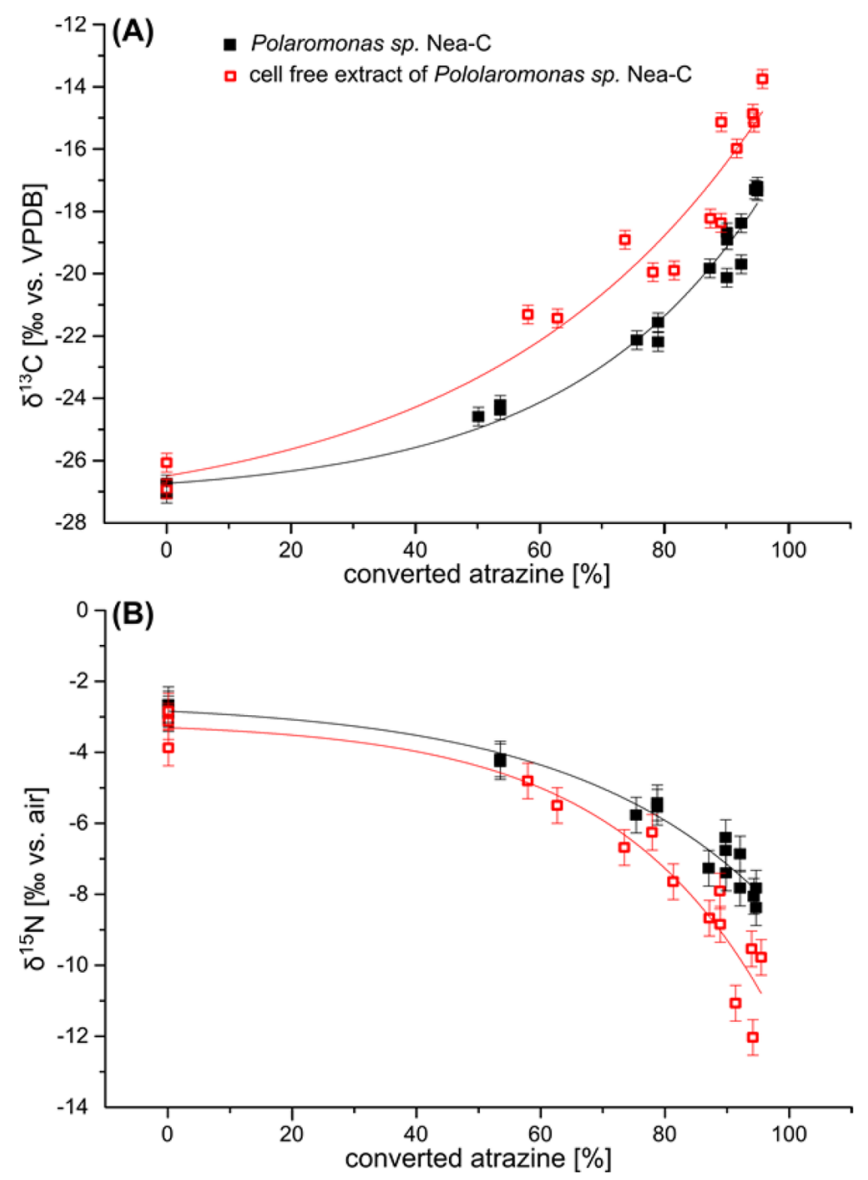

Figure 1. Isotope fractionation in Polaromonas sp. Nea-C which depends on the integrity of the cell envelope. The biodegradation of atrazine by the Gram-negative Polaromonas sp. Nea-C (black full squares) leads to considerably less isotope fractionation than the atrazine degradation of cell-free extracts of Polaromonas sp. Nea-C (red empty squares) both for normal carbon (A) and inverse nitrogen (B) isotope fractionation. Error bars represent typical standard deviations of carbon $( \pm 0.3 \% \circ)$ and nitrogen $( \pm 0.5 \%)$ isotope analysis.

with the difference that Chelatobacter heintzii degrades atrazine with a different enzyme-AtzA ${ }^{32}$ - but still via the same acidic hydrolysis (Table 1). This raises the question whether these different enzymes from different species (AtzA, TrzN from Polaromonas sp. Nea-C, and TrzN from A. aurescens TC1) have different transition states and thus different enrichment factors, or whether the difference in isotope fractionation is attributable to physiological differences in the cell envelope that are characteristic of Gram-positive (A. aurescens TC1) versus Gram-negative (Chelatobacter heintzii and Polaromonas $s p$. Nea-C) bacterial strains.

Strong Enzymatic Isotope Fractionation Was Masked by Mass Transfer Limitations. Indeed, although the sequences of $\operatorname{trzN}$ genes from Polaromonas $s p$. Nea-C versus A. aurescens $\mathrm{TC} 1$ are highly similar (see above), it cannot be strictly excluded that subtle differences in the protein structure of even TrzN could be responsible for the differences in isotope fractionation. For example, in a recent study by Schürner et al., ${ }^{38}$ we observed that single point mutations in the trzN gene can lead to subtle changes in isotope fractionation. We therefore prepared cell-free extracts of Polaromonas $s p$. Nea-C to degrade atrazine to hydroxyatrazine and followed the degradation with CSIA. As the hydrolysis of the atrazine 

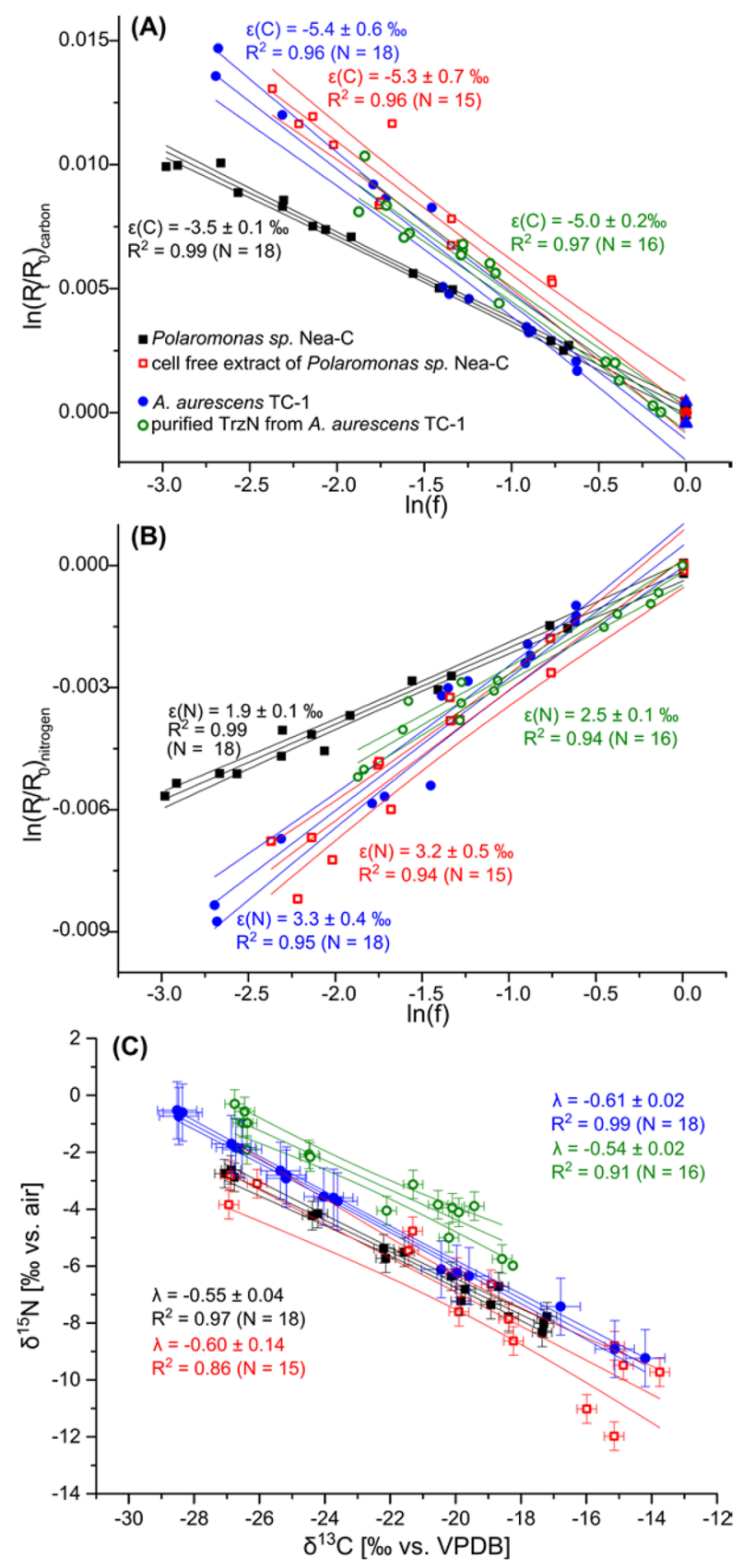

Figure 2. Rate-limiting mass transfer across the Gram-negative cell envelope, revealed by isotope fractionation. Normal carbon isotope fractionation factors $(\varepsilon(\mathrm{C}))(\mathrm{A})$ and inverse nitrogen isotope fractionation factors $(\varepsilon(\mathrm{N}))$ (B) were determined by the Rayleigh equation. Enrichment factors in cell-free extracts of Polaromonas sp. Nea-C (red empty squares) were identical to those with whole cells of Gram-positive $A$. aurescens $\mathrm{TC}^{32}$ (blue full circles) and purified $\mathrm{TrzN}^{38}$ (green empty circles) indicating that an identical enzyme reaction was at work. In contrast, smaller isotope fractionation was observed in degradation with intact cells of Gram-negative Polaromonas sp. Nea-C (black full squares). (C) Slope $\lambda$ in the dual element isotope plot was similar for all degradation experiments, indicating that a common reaction mechanism (acidic hydrolysis) and similar transition state architecture is present in TrzN of both bacteria. Taken together, this indicates that the isotope effect of the enzyme reaction was partially masked by mass transfer across the cell envelope in Polaromonas sp. Nea-C. This nonfractionating step affects carbon and nitrogen fractionation in the same way so that the dual element isotope slope $\lambda$ stays constant even though the enrichment factors are smaller. Error bars represent typical standard deviations of carbon
Figure 2. continued

$( \pm 0.3 \% 0)$ and nitrogen $( \pm 0.5 \%)$ isotope analysis (except for data from degradation with $A$. aurescens TC1 where total uncertainties are given).

$\mathrm{C}-\mathrm{Cl}$ bond does not depend on any cofactors or energy in the form of ATP, the cell-free extracts were highly active, atrazine turnover was fast (SI Figure S2) and was accompanied by strong isotope fractionation, as shown in Figure 1. The isotope fractionation in cell-free extracts was considerably larger than in whole cells and gave enrichment factors $\varepsilon(\mathrm{C})=-5.3 \pm 0.7 \%$ and $\varepsilon(\mathrm{N})=3.2 \pm 0.5 \%$ o that again were indistinguishable from those of $A$. aurescens TC1 (Figure 2A, B). ${ }^{32}$ This isotope fractionation was also similar to that of recombinant TrzN from A. aurescens TC1 (instead of cell-free extracts) and of abiotic acidic hydrolysis (Table 1 ). ${ }^{32,38}$ Further, the slope of the dual element isotope plot $\lambda \approx \varepsilon(\mathrm{N}) / \varepsilon(\mathrm{C})$ was the same for the degradation with Polaromonas sp. Nea-C, A. aurescens TC1, and the cell-free extract of Polaromonas $s p$. Nea-C $(\lambda=-0.55 \pm$ $0.04,-0.60 \pm 0.02$, and $-0.61 \pm 0.14$, respectively) (Figure $2 \mathrm{C}$ ) and was similar to those with recombinant TrzN and abiotic acidic hydrolysis (Table 1). ${ }^{32,38}$ This similarity in intrinsic isotope fractionation strongly suggests that the same enzymatic reaction and same transition state prevailed but that this isotope fractionation was partially masked by a nonisotope fractionating step. This masking occurred only in whole cells with intact cell envelope, but not in cell-free extracts of Polaromonas $s p$. Nea-C. Such masking effects have previously be invoked to be attributable to (i) artificial high cell densities, ${ }^{49}$ (ii) diffusion through water, or (iii) retention in extracellular polymeric substance (EPS). These alternative explanations can be ruled out, however, since (i) our cell densities were small in comparison with Kampara et al.'s study, ${ }^{49}$ (ii) the atrazine diffusion in water is fast compared to diffusion in lipid membranes, ${ }^{31}$ and (iii) Polaromonas sp. Nea-C does not form EPS. Consequently, we conclude that it was mass transfer across the cell envelope that was the partially rate-limiting step in biodegradation of atrazine by the Gram-negative Polaromonas $s p$. Nea-C, but not by the Gram-positive $A$. aurescens TC1.

Passive Processes Dominate Atrazine Uptake into the Cell. The phenomenon that organic pollutant uptake can mask isotope fractionation has already been described by Qiu et al. where active transport along the proton motive force was the rate-determining step for phenoxy acid degradation at high concentrations. ${ }^{27}$ However, no specific transporters for atrazine are known and nonpolar molecules like atrazine with a relatively high $\log \mathrm{P}$ value of 2.6 can even permeate the phospholipid bilayer directly. ${ }^{50,51}$ A phosphotransferase uptake system $^{52}$ can be ruled out, as atrazine does not undergo phosphorylation. Other plausible uptake pathways are active transport across the lipid bilayer driven by ATP hydrolysis or by an electrochemical gradient. ${ }^{53-55}$ To explore these hypotheses, atrazine degradation rates with Polaromonas $s p$. Nea-C and $A$. aurescens TC1 were compared for both strains with and without addition of KCN. Cyanide is known to inhibit cytochrome $\mathrm{c}$ so that the proton gradient collapses and ATP production ceases. As shown in Figure 3, the initial atrazine degradation rates in Polaromonas sp. Nea-C and A. aurescens TC1 were not influenced by $0.25 \mathrm{mM} \mathrm{KCN}$. We conclude that atrazine degradation does not depend on active transport by ATP or the proton motive force. Thus, passive processes driven 


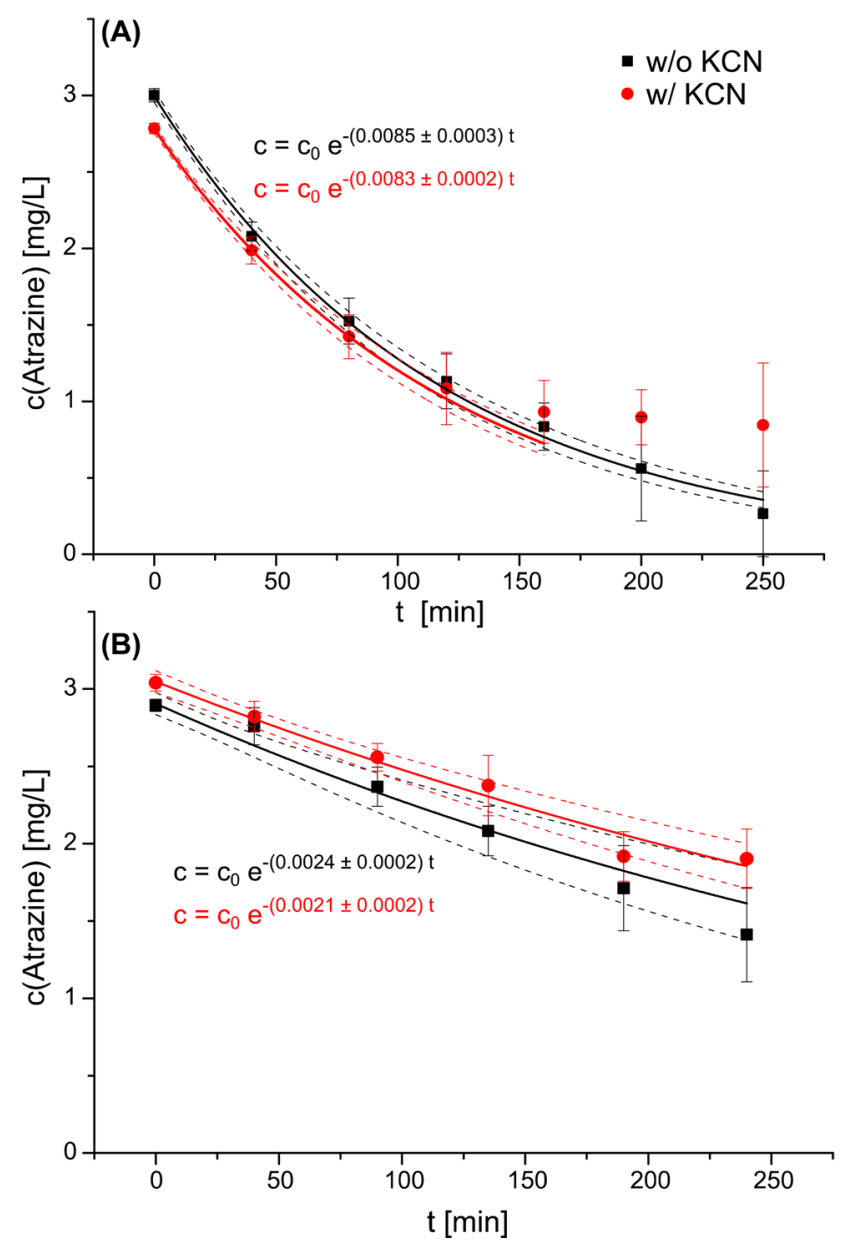

Figure 3. The degradation rates of both species ((A) A. aurescens TC-1 and (B) Polaromonas sp. Nea-C) were the same for control cells (black squares) and cells treated with $0.25 \mathrm{mM} \mathrm{KCN}$ (red circles). A pseudofirst-order reaction kinetics was assumed, as the concentration range was well below the Michaelis-Menten constant $K_{\mathrm{M}}$ of $\mathrm{TrzN}^{36}$ Cyanide was added to inhibit cytochrome $\mathrm{c}$ to prevent formation of a proton gradient so that energy production ceases. The hydrolytic enzyme TrzN does not depend on ATP or other cofactors and is not inhibited. The degradation rates were reduced in A. aurescens TC-1 $150 \mathrm{~min}$ after KCN addition, indicating endogenous decay of TrzN. The fits of the first order rate constant in parts A and B are statistically not different at the 0.05 significance level.

by the atrazine gradient led to atrazine uptake, e.g. through facilitated transport with porins or permeation of the membrane itself. $^{51,56}$ Note that we did not study isotope fractionation here, because (i) this concentration range was also covered in the previous degradation (SI Figure S1) and (ii) the isotope fractionation was not concentration dependent in this concentration range (Figure 2A, B; Table 1) so that the same isotopic enrichment factor is expected.

Implications for the Application of CSIA in Field Studies. When mass transfer masks the enzymatic reaction, this does not only limit biodegradation in the environment but also has implications for the in situ assessment of biodegradation based on CSIA: pollutant turnover via the Rayleigh equation can best be estimated if isotope enrichment factors associated with a certain degradation pathway are constant and show little variation. However, as demonstrated in this study and by Renpenning et al., ${ }^{28}$ the isotope fractionation does not only depend on the reaction mechanism, but also on masking of the enzymatic reaction by mass transfer across the Gram-negative cell envelope. This leads to subtle differences in enrichment factors even for the same enzymatic reaction and introduces a small additional uncertainty in biodegradation assessments by CSIA in the field. ${ }^{57}$ As a consequence, identification of the primary degradation pathway and the primary degrading strain would help to relate isotope fractionation in the field to isotope fractionation in the lab. A different strategy would be to use the enrichment factor determined under optimal conditions where mass transfer limitations are absent as a conservative estimate of biodegradation. This may underestimate biodegradation when the mass transfer becomes more and more rate-limiting at low concentrations. ${ }^{31}$ In contrast, the possibility to distinguish different processes and reaction pathways with dual element isotope plots remains valid, as long as the mass transfer across the cell envelope does not mask the enzymatic isotope fractionation completely.

Therefore, we theoretically analyzed how the isotope fractionation during atrazine degradation by Polaromonas $s p$. Nea-C is affected by decreasing concentrations. This concentration-dependent observable isotope enrichment factor $\varepsilon^{*}$ can be modeled with a mathematical framework proposed by Thullner et al. for the case that mass transfer masks the intrinsic enzymatic fractionation factor $\varepsilon .^{30}$ This framework correlates the specific affinity of the enzyme $a=q_{\max } K_{\mathrm{M}}{ }^{-1}$ with the mass transfer coefficient across the cell envelope $k_{\mathrm{tr}}$. When the influx (determined by $k_{\text {tr }}$ ) is slower than the enzymatic turnover (determined by $a$ ) the fractionation factor $\varepsilon$ will be masked which leads to a smaller observable enrichment factor $\varepsilon^{*}\left(\varepsilon^{*}<\varepsilon\right)$. We used numerical modeling (see experimental section above) to fit the time-dependent enrichment in ${ }^{13} \mathrm{C}$ associated with the atrazine concentration decrease (eqs 4 and 5; SI Figure S3). Thus, we were able to estimate the parameters for Thullner et al.'s model: $q_{\max }=2.7 \mathrm{nmol} /(\mathrm{L} \mathrm{s})$ which gives $a$ $=0.14 \mathrm{~s}^{-1}$ and the mass transfer coefficient across the cell envelope $k_{\mathrm{tr}}=1.6 \times 10^{-4} \mathrm{~s}^{-1}$. We validated our modeling approach for $k_{\mathrm{tr}}$ by calculating the lipid diffusion coefficient $D_{\text {lip }}$ according to eq 6 where the cell shape and physiology is taken into account, to compare with literature values. Indeed, the calculated atrazine lipid diffusion coefficient $D_{\text {lip }}=1.3 \times 10^{-17}$ $\mathrm{m}^{2} / \mathrm{s}$ was, as expected, smaller, but in the same range as $D_{\text {lip }}$ recently observed for atrazine in a single lipid bilayer of the Gram-positive $A$. aurescens TC1. ${ }^{31}$ This demonstrates that our modeling approach yields realistic values for $k_{\mathrm{tr}}$ allowing us to use $k_{\mathrm{tr}}$ to predict a decreasing observed fractionation factor $\varepsilon^{*}$ with decreasing atrazine concentrations according to Thullner et al. $^{30}$ Consistent with our experimental results, at a concentration of $4 \mathrm{mg} / \mathrm{L}$ the enzymatic fractionation factor of $\varepsilon=-5.3 \%$ is already reduced to $\varepsilon^{*}=-3.5 \%$, and it is predicted to be further reduced to below $-3 \%$ already at an atrazine concentration of $1 \mathrm{mg} / \mathrm{L}$.

Pollutant Mass Transfer of Nonpolar Pollutants May Be Rate-Limiting for Biodegradation in Gram-negative Bacteria. Our results strongly suggest that the specific physiology of the Gram-negative Polaromonas $s p$. Nea-C with its additional restrictive outer membrane limited the influx of atrazine. In contrast, isotope fractionation in Gram-positive A. aurescens TC1 was fully observable, demonstrating the absence of mass transfer limitation. This shows that the permeation of the cell envelope is partially rate-determining for atrazine degradation by Polaromonas sp. Nea-C already at high concentrations. Furthermore, Renpenning et al. show that the 
mass transfer across the cell envelope of Gram-negative bacteria affects biodegradation of chlorinated ethenes. ${ }^{28}$ Taken together, the difference between Gram-positive and Gram-negative physiology might also affect the nature of nonpolar pollutant biodegradation in the environment: while a restrictive outer membrane protects Gram-negative bacteria from xenobiotics ${ }^{58}$ and from the toxicity of compounds with high $\log P$ values, ${ }^{59,60}$ it might also lower the supply of nonpolar pollutants as nutrients when transporters are absent.

\section{ASSOCIATED CONTENT}

\section{S Supporting Information}

The Supporting Information is available free of charge on the ACS Publications website at DOI: 10.1021/acs.est.7b06599.

More detailed experimental section, graphs of the degradation experiments, and a table of TrzN sequence similarities (PDF)

\section{AUTHOR INFORMATION}

\section{Corresponding Author}

*E-mail: m.elsner@tum.de. Tel.: +49 89 2180-78232.

ORCID

Martin Elsner: 0000-0003-4746-9052

\section{Funding}

This work was funded by an ERC consolidator grant ("MicroDegrade", grant no. 616861) awarded by the European Research Council.

\section{Notes}

The authors declare no competing financial interest.

\section{REFERENCES}

(1) Schwarzenbach, R. P.; Escher, B. I.; Fenner, K.; Hofstetter, T. B.; Johnson, C. A.; von Gunten, U.; Wehrli, B. The Challenge of Micropollutants in Aquatic Systems. Science 2006, 313 (5790), 10721077.

(2) Dai, N.; Mitch, W. A. Relative Importance of N-Nitrosodimethylamine Compared to Total N-Nitrosamines in Drinking Waters. Environ. Sci. Technol. 2013, 47 (8), 3648-3656.

(3) Rosal, R.; Rodríguez, A.; Perdigón-Melón, J. A.; Petre, A.; GarcíaCalvo, E.; Gómez, M. J.; Agüera, A.; Fernández-Alba, A. R. Occurrence of emerging pollutants in urban wastewater and their removal through biological treatment followed by ozonation. Water Res. 2010, 44 (2), 578-588.

(4) Barbieri, M.; Carrera, J.; Ayora, C.; Sanchez-Vila, X.; Licha, T.; Noedler, K.; Osorio, V.; Perez, S.; Koeck-Schulmeyer, M.; Lopez de Alda, M.; Barcelo, D. Formation of diclofenac and sulfamethoxazole reversible transformation products in aquifer material under denitrifying conditions: Batch experiments. Sci. Total Environ. 2012, 426, 256-263.

(5) Battaglin, W. A.; Meyer, M. T.; Kuivila, K. M.; Dietze, J. E. Glyphosate and Its Degradation Product AMPA Occur Frequently and Widely in U.S. Soils, Surface Water, Groundwater, and Precipitation. J. Am. Water Resour. Assoc. 2014, 50 (2), 275-290.

(6) Loos, R.; Locoro, G.; Comero, S.; Contini, S.; Schwesig, D.; Werres, F.; Balsaa, P.; Gans, O.; Weiss, S.; Blaha, L.; Bolchi, M.; Gawlik, B. M. Pan-European survey on the occurrence of selected polar organic persistent pollutants in ground water. Water Res. 2010, 44 (14), 4115-4126.

(7) Pflanzenschutzmittel-Metaboliten Vorkommen and Bewertung: Fachtagung des Bayerischen Landesamtes für Umwelt; 2008

(8) Selim, H. M. Modelling kinetic retention of atrazine and metribuzin in soil 1. Soil Sci. 2004, 169, 25-34.

(9) Morvan, X.; Mouvet, C.; Baran, N.; Gutierrez, A. Pesticides in the groundwater of a spring draining a sandy aquifer: Temporal variability of concentrations and fluxes. J. Contam. Hydrol. 2006, 87 (3-4), 176190.

(10) Graymore, M.; Stagnitti, F.; Allinson, G. Impacts of atrazine in aquatic ecosystems. Environ. Int. 2001, 26 (7-8), 483-495.

(11) Button, D. K.; Robertson, B.; Gustafson, E.; Zhao, X. M. Experimental and theoretical bases of specific affinity, a cytoarchitecture-based formulation of nutrient collection proposed to supercede the Michaels-Menten paradigm of microbial kinetics. Appl. Environ. Microbiol. 2004, 70 (9), 5511-5521.

(12) Bosma, T. N. P.; Middeldorp, P. J. M.; Schraa, G.; Zehnder, A. J. B. Mass Transfer Limitation of Biotransformation: Quantifying Bioavailability. Environ. Sci. Technol. 1997, 31 (1), 248-252.

(13) Wick, L. M.; Quadroni, M.; Egli, T. Short- and long-term changes in proteome composition and kinetic properties in a culture of Escherichia coli during transition from glucose-excess to glucoselimited growth conditions in continuous culture and vice versa. Environ. Microbiol. 2001, 3 (9), 588-599.

(14) Hunkeler, D.; Elsner, M., Principles and Mechanisms of Isotope Fractionation. In Environmental Isotopes in Biodegradation and Bioremediation; Aelion, C. M., Hohener, P., Hunkeler, D., Aravena, R., Eds.; CRC Press: Boca Raton, London, NY, 2010.

(15) Melander, L.; Saunders, W. H. Reaction rates of isotopic molecules; John Wiley: New York, 1980; p 331.

(16) Hoefs, J. Theoretical and Experimental Principles. In Stable isotope geochemistry, 3rd ed.; Wyllie, P. J., Ed.; Springer-Verlag: Chicago, 1987; pp 1-25.

(17) Schmidt, H. L. Fundamentals and systematics of the nonstatistical distributions of isotopes in natural compounds. Naturwissenschaften 2003, 90 (12), 537-552.

(18) Northrop, D. B. The expression of isotope effects on enzymecatalyzed reactions. Annu. Rev. Biochem. 1981, 50, 103-131.

(19) Nijenhuis, I.; Andert, J.; Beck, K.; Kastner, M.; Diekert, G.; Richnow, H. H. Stable isotope fractionation of tetrachloroethene during reductive dechlorination by Sulfurospirillum multivorans and Desulfitobacterium sp. Strain PCE-S and abiotic reactions with cyanocobalamin. Appl. Environ. Microbiol. 2005, 71 (7), 3413-3419.

(20) Farquhar, G. D.; Ehleringer, J. R.; Hubick, K. T. Carbon Isotope Discrimination and Photosynthesis. Annu. Rev. Plant Physiol. Plant Mol. Biol. 1989, 40, 503-537.

(21) O'Leary, M. H. Carbon Isotopes in Photosynthesis. BioScience 1988, 38 (5), 328-336.

(22) Rees, C. E. A steady-state model for sulphur isotope fractionation in bacterial reduction processes. Geochim. Cosmochim. Acta 1973, 37 (5), 1141-1162.

(23) Brunner, B.; Bernasconi, S. M.; Kleikemper, J.; Schroth, M. H. A model for oxygen and sulfur isotope fractionation in sulfate during bacterial sulfate reduction processes. Geochim. Cosmochim. Acta 2005, 69 (20), 4773-4785.

(24) Wing, B. A.; Halevy, I. Intracellular metabolite levels shape sulfur isotope fractionation during microbial sulfate respiration. Proc. Natl. Acad. Sci. U. S. A. 2014, 111 (51), 18116-18125.

(25) Kritee, K.; Sigman, D. M.; Granger, J.; Ward, B. B.; Jayakumar, A.; Deutsch, C. Reduced isotope fractionation by denitrification under conditions relevant to the ocean. Geochim. Cosmochim. Acta 2012, 92 (0), 243-259.

(26) Wunderlich, A.; Meckenstock, R.; Einsiedl, F. Effect of Different Carbon Substrates on Nitrate Stable Isotope Fractionation During Microbial Denitrification. Environ. Sci. Technol. 2012, 46 (9), 48614868.

(27) Qiu, S.; Gözdereliler, E.; Weyrauch, P.; Lopez, E. C. M.; Kohler, H.-P. E.; Sørensen, S. R.; Meckenstock, R. U.; Elsner, M. Small 13C/ 12C Fractionation Contrasts with Large Enantiomer Fractionation in Aerobic Biodegradation of Phenoxy Acids. Environ. Sci. Technol. 2014, 48 (10), 5501-5511.

(28) Renpenning, J.; Rapp, I.; Nijenhuis, I. Substrate hydrophobicity and cell composition influence the extent of rate limitation and masking of isotope fractionation during microbial reductive dehalogenation of chlorinated ethenes. Environ. Sci. Technol. 2015, 49 (7), 4293-4301. 
(29) Kampara, M.; Thullner, M.; Richnow, H. H.; Harms, H.; Wick, L. Y. Impact of Bioavailability Restrictions on Microbially Induced Stable Isotope Fractionation. 2. Experimental Evidence. Environ. Sci. Technol. 2008, 42 (17), 6552-6558.

(30) Thullner, M.; Kampara, M.; Richnow, H. H.; Harms, H.; Wick, L. Y. Impact of Bioavailability Restrictions on Microbially Induced Stable Isotope Fractionation. 1. Theoretical Calculation. Environ. Sci. Technol. 2008, 42 (17), 6544-6551.

(31) Ehrl, B. N.; Kundu, K.; Gharasoo, M.; Marozava, S.; Elsner, M. Rate-limiting mass transfer in micropollutant degradation revealed by isotope fractionation. Nature Geoscience 2018, in preparation for publication.

(32) Meyer, A. H.; Penning, H.; Elsner, M. C and N isotope fractionation suggests similar mechanisms of microbial atrazine transformation despite involvement of different Enzymes (AtzA and TrzN). Environ. Sci. Technol. 2009, 43 (21), 8079-8085.

(33) Bernstein, A.; Ronen, Z.; Adar, E.; Nativ, R.; Lowag, H.; Stichler, W.; Meckenstock, R. U. Compound-Specific Isotope Analysis of RDX and Stable Isotope Fractionation during Aerobic and Anaerobic Biodegradation. Environ. Sci. Technol. 2008, 42 (21), 7772-7777.

(34) Hunkeler, D.; Van Breukelen, B. M.; Elsner, M. Modeling Chlorine Isotope Trends during Sequential Transformation of Chlorinated Ethenes. Environ. Sci. Technol. 2009, 43 (17), 6750-6756.

(35) Maier, M. P.; De Corte, S.; Nitsche, S.; Spaett, T.; Boon, N.; Elsner, M. C \& N Isotope Analysis of Diclofenac to Distinguish Oxidative and Reductive Transformation and to Track Commercial Products. Environ. Sci. Technol. 2014, 48 (4), 2312-2320.

(36) Shapir, N.; Pedersen, C.; Gil, O.; Strong, L.; Seffernick, J.; Sadowsky, M. J.; Wackett, L. P. TrzN from Arthrobacter aurescens TC1 Is a zinc amidohydrolase. J. Bacteriol. 2006, 188 (16), 58595864.

(37) Devers, M.; Azhari, N. E.; Kolic, N.-U.; Martin-Laurent, F. Detection and organization of atrazine-degrading genetic potential of seventeen bacterial isolates belonging to divergent taxa indicate a recent common origin of their catabolic functions. FEMS Microbiol. Lett. 2007, 273 (1), 78-86.

(38) Schürner, H. K. V.; Seffernick, J. L.; Grzybkowska, A.; DybalaDefratyka, A.; Wackett, L. P.; Elsner, M. Characteristic Isotope Fractionation Patterns in s-Triazine Degradation Have Their Origin in Multiple Protonation Options in the s-Triazine Hydrolase TrzN. Environ. Sci. Technol. 2015, 49 (6), 3490-3498.

(39) Reinnicke, S.; Juchelka, D.; Steinbeiss, S.; Meyer, A. H.; Hilkert, A.; Elsner, M. Gas chromatography-isotope ratio mass spectrometry (GC-IRMS) of recalcitrant target compounds: performance of different combustion reactors and strategies for standardization. Rapid Commun. Mass Spectrom. 2012, 26 (9), 1053-1060.

(40) Coplen, T. B. Guidelines and recommended terms for expression of stable-isotope-ratio and gas-ratio measurement results. Rapid Commun. Mass Spectrom. 2011, 25 (17), 2538-2560.

(41) Coplen, T. B.; Krouse, H. R.; Boehlke, J. K. Reporting of nitrogen-isotope abundances. Pure Appl. Chem. 1992, 64, 907-908.

(42) Michaelis, L.; Menten, M. L. Die Kinetik der Invertinbindung. Biochemische Zeitschrift 1913, 49, 333-369.

(43) Gharasoo, M.; Centler, F.; Van Cappellen, P.; Wick, L. Y.; Thullner, M. Kinetics of Substrate Biodegradation under the Cumulative Effects of Bioavailability and Self-Inhibition. Environ. Sci. Technol. 2015, 49 (9), 5529-5537.

(44) Best, J. B. The inference of intracellular enzymatic properties from kinetic data obtained on living cells. I. Some kinetic considerations regarding an enzyme enclosed by a diffusion barrier. J. Cell. Comp. Physiol. 1955, 46 (1), 1-27.

(45) Gharasoo, M.; Thullner, M.; Elsner, M. Introduction of a new platform for parameter estimation of kinetically complex environmental systems. Environmental Modelling \& Software 2017, 98 (Supplement C), 12-20.

(46) Stenzel, A.; Goss, K. U.; Endo, S. Determination of Polyparameter Linear Free Energy Relationship (pp-LFER) Substance Descriptors for Established and Alternative Flame Retardants. Environ. Sci. Technol. 2013, 47 (3), 1399.
(47) Mongodin, E. F.; Shapir, N.; Daugherty, S. C.; DeBoy, R. T.; Emerson, J. B.; Shvartzbeyn, A.; Radune, D.; Vamathevan, J.; Riggs, F.; Grinberg, V.; Khouri, H.; Wackett, L. P.; Nelson, K. E.; Sadowsky, M. J. Secrets of Soil Survival Revealed by the Genome Sequence of Arthrobacter aurescens TC1. PLoS Genet. 2006, 2 (12), e214.

(48) Zhang, Z.; Schwartz, S.; Wagner, L.; Miller, W. A Greedy Algorithm for Aligning DNA Sequences. J. Comput. Biol. 2000, 7 (12), 203-214.

(49) Kampara, M.; Thullner, M.; Harms, H.; Wick, L. Y. Impact of cell density on microbially induced stable isotope fractionation. Appl. Microbiol. Biotechnol. 2009, 81 (5), 977-985.

(50) Endo, S.; Escher, B. I.; Goss, K.-U. Capacities of Membrane Lipids to Accumulate Neutral Organic Chemicals. Environ. Sci. Technol. 2011, 45 (14), 5912-5921.

(51) Parales, R. E.; Ditty, J. L. Substrate Transport. In Handbook of Hydrocarbon and Lipid Microbiology; Timmis, K. N., Ed.; Springer: Berlin, Heidelberg, 2010; pp 1545-1553.

(52) Deutscher, J.; Francke, C.; Postma, P. W. How Phosphotransferase System-Related Protein Phosphorylation Regulates Carbohydrate Metabolism in Bacteria. Microbiology and Molecular Biology Reviews 2006, 70 (4), 939-1031.

(53) Nichols, N. N.; Harwood, C. S. PcaK, a high-affinity permease for the aromatic compounds 4-hydroxybenzoate and protocatechuate from Pseudomonas putida. J. Bacteriol. 1997, 179 (16), 5056-61.

(54) Groenewegen, P. E.; Driessen, A. J.; Konings, W. N.; de Bont, J. A. Energy-dependent uptake of 4-chlorobenzoate in the coryneform bacterium NTB-1. J. Bacteriol. 1990, 172 (1), 419-423.

(55) Locher, H. H.; Poolman, B.; Cook, A. M.; Konings, W. N. Uptake of 4-toluene sulfonate by Comamonas testosteroni T-2. J. Bacteriol. 1993, 175 (4), 1075-1080.

(56) Lambert, P. A. Cellular impermeability and uptake of biocides and antibiotics in Gram-positive bacteria and mycobacteria. J. Appl. Microbiol. 2002, 92, 46S-54S.

(57) Mancini, S. A.; Hirschorn, S. K.; Elsner, M.; LacrampeCouloume, G.; Sleep, B. E.; Edwards, E. A.; SherwoodLollar, B. Effects of Trace Element Concentration on Enzyme Controlled Stable Isotope Fractionation during Aerobic Biodegradation of Toluene. Environ. Sci. Technol. 2006, 40 (24), 7675-7681.

(58) Delcour, A. H. Outer Membrane Permeability and Antibiotic Resistance. Biochim. Biophys. Acta, Proteins Proteomics 2009, 1794 (5), 808-816.

(59) Sikkema, J.; de Bont, J. A.; Poolman, B. Mechanisms of membrane toxicity of hydrocarbons. Microbiol. Rev. 1995, 59 (2), 201-22.

(60) Isken, S.; de Bont, J. A. M. Bacteria tolerant to organic solvents. Extremophiles 1998, 2 (3), 229-238. 